\title{
Comparing SCIG and DFIG for Wind Generating Conditions in Macedonia
}

\author{
Sanja Vitanova, e-mail:sanja_sr_2000@yahoo.com \\ Vlatko Stoilkov, e-mail: stoilkov@ feit.ukim.edu.mk \\ Vladimir Dimcev, e-mail: vladim@feit.ukim.edu.mk
}

Contact address: Faculty of Electrical Engineering and Information Technology, Karpos II bb, Skopje, Macedonia

Abstract - The wind energy has become the most potential renewable energy source recently. The technological and industrial development in the wind power generation indicates that wind power should be seen as one of the main domestic sources for electricity generation in all countries. This paper gives an overall observation of the most commonly used electrical machines, i.e. the squirrel cage induction generators (SCIG) and doubly fed induction generators (DFIG) in the wind generation systems. Using the Matlab/Simulink, a simulation of wind farm with the two types of generators has been made in order to compare the results and to comment on the best option based on the output characteristics of the generator and wind turbine.

\section{Introduction}

European dependency on imported fossil fuel as well as Macedonian as a part of Europe has become a threat to economic stability increasing uncertainties over energy prices. Environmental effects of fossil based power plants add another dimension of the problem. These power plants load the atmosphere with greenhouse gases resulting in global warming and climate changes.

For these reasons one of the key points on the European energy policy agenda is to increase the share of the energy demand that is covered from the renewable energy sources. According to the European Commission by 2020, 34\% of EU energy demands will be covered by renewable energy sources (RES) and wind energy will meet $12 \%$ of EU electricity demands by 2020.

Most promising from the RES are the wind and solar energy. The difference between the conventional sources and these sources is that the primary energy of the RES has stochastic nature and the fluctuations are uncontrollable and permanent. Wind power is the most potential renewable source, very promising and mature renewable technology. Electricity is the commonly used energy source in the industry and in the private sector in Macedonia. Macedonia is highly dependent on energy imports (oil, natural gas, electricity) which have grown rapidly in recent years. The whole energy sources in Macedonia are based on conventional power plants. The approximate structure of coverage is $75 \%$ domestic electricity production (where $80 \%$ from coil TPP and 20\% HPP) and $25 \%$ is provided by import. Inclusion of the renewable energy for electricity production will allow improved and more stable electricity supply and will reduce the energy imports.

\section{Wind turbines}

Most of the wind turbines use induction generators because of their advantageously characteristics. Induction machines are simple and rugged in construction, offer impressive efficiency under varying operating conditions, relatively inexpensive and require minimum maintenance and care. Characteristics of these generators like the over speed capability make them suitable for the wind turbine application.

The wind power captured by the turbine rotor and converted to mechanical power is dependent on the average wind speed over the rotor surface and the rotational speed of the rotor. Therefore maximum wind energy capture can be achieved only if the rotor speed is varied tracking the changes of the wind. Variable speed operation of the wind turbines is necessary to gain high efficiency in the generating systems. Additional advantages of the variable speed operation are the reduction of the drive train mechanical stresses which permits the use of lighter transmissions, the improvement of the output power quality and the reduction of the noise emitted from the wind turbines.

The induction generators that are used in the wind turbine are usually squirrel cage induction generators (SCIG) and in nowadays doubly fed induction generators (DFIG). Doubly fed induction generators have windings on stator and rotor where both of the windings transfer significant power between the shaft and the electrical system.

\section{Equivalent circuit of asynchronous machines}

It is often necessary to make quantitative predictions about the behavior of the asynchronous machines under different operating conditions. For this purpose it is useful to present an equivalent circuit for the machines in operating mode in a stationary condition (Fig.1). 


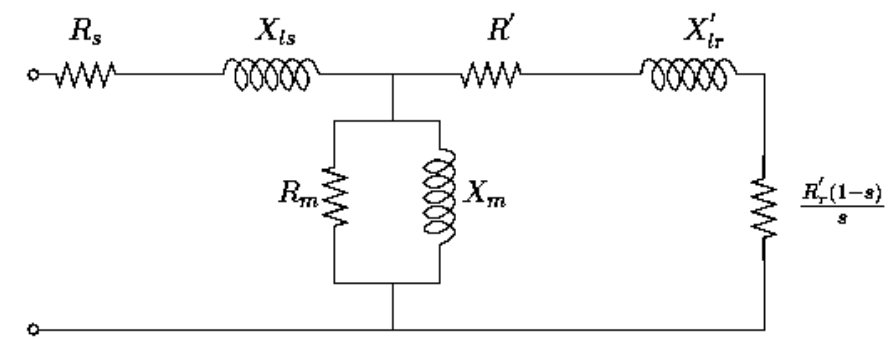

Fig.1. Equivalent circuit for IG in stationary regime

The asynchronous machines are built from two separate electrical systems that are coupled by mutual magnetic flux. In the primary winding $\mathrm{W}_{1}$, voltage $\mathrm{E}_{1}$ is induced and in the secondary winding $\mathrm{W}_{2}$ voltage $\mathrm{E}_{2}$ is induced causing current in the rotor $I_{2}=\frac{E_{2 s}}{Z_{2 s}}$.

While the current $I_{1}$ is flowing through the stator winding, it causes active (rotor) resistance and inductive (leakage) resistance voltage drop and the current $\mathrm{I}_{2}$ that flows through the rotor circuit causes the same resistances in the rotor circuit. In the rotor circuit there is an additional resistance beside the active resistance that defines the load of the machines.

$\mathrm{R}_{2}{ }_{2}$ and $\mathrm{X}_{2}$ refer to the resistance of the rotor and leakage resistance referred to the stator side. The amplitude of the rotor current is

$I_{2}=\frac{s \cdot E_{1}}{R_{2}+j X_{2} \cdot s}$

From the equivalent circuit it can be seen that losses in $R_{s}$ represent losses in the stator while losses in $R_{m}$ are losses in iron. Energy consumed by the rotor circuit represents all other forms of consumption of energy - mechanical output, losses in windings, frictional losses, losses in copper.

\section{A. Equivalent Circuit for DFIG}

The figure below (Fig.2) shows the equivalent circuit of a doubly fed machine in a fixed reference frame, for steady state operation.

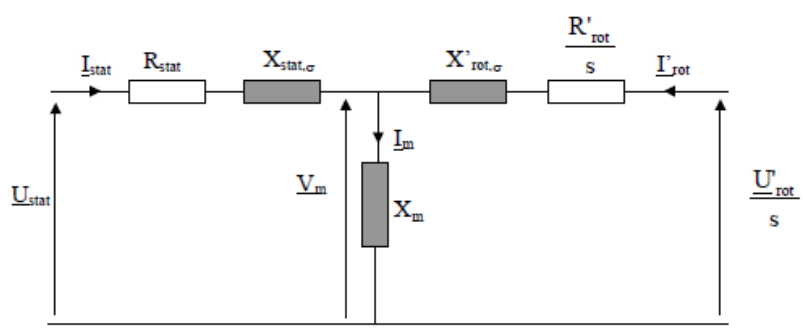

Fig.2. Equivalent circuit for DFIG in a fix reference frame

The rotor quantities are referred to the stator:

$$
\begin{aligned}
& \underline{I}_{r o t}^{\prime}=\frac{N_{r o t}}{N_{\text {stat }}} \underline{I}_{r o t}, \underline{U}_{r o t}^{\prime}=\frac{N_{\text {stat }}}{N_{r o t}} \underline{U}_{r o t}, \\
& R_{r o t}^{\prime}=\frac{N_{\text {stat }}^{2}}{N_{r o t}^{2}} R_{r o t}, X_{r o t}^{\prime}=\frac{N_{\text {stat }}^{2}}{N_{r o t}^{2}} X_{r o t}
\end{aligned}
$$

where $\mathrm{N}$ is the number of turns in the windings

The circuit allows to calculate the steady state values of rotor current and voltage. Special attention is paid to the calculation of the rotor apparent power as a function of stator active and reactive current, as the rotor apparent power has a high impact on the required rating of the rotor power electronic converter.

The stator and voltage equations in steady state regime are:

$$
\begin{aligned}
& \underline{U}_{\text {stat }}=\left(R_{\text {stat }}+j \cdot X_{\text {stat }}\right) \cdot \underline{I}_{\text {stat }}+j \cdot X_{m} \cdot \underline{I}_{r o t}^{\prime} \\
& \underline{U}_{r o t}^{\prime}=\left(R_{r o t}^{\prime}+j \cdot s \cdot X_{r o t}^{\prime}\right) \cdot \underline{I}_{r o t}^{\prime}+j \cdot s \cdot X_{m} \cdot \underline{I}_{s t a t}^{\prime} \\
& X_{s t a t}=X_{m}+X_{s t a t, \sigma}, X_{r o t}^{\prime}=X_{m}+X_{r o t, \sigma}^{\prime}
\end{aligned}
$$

The rotor current can be calculated from $\underline{\mathrm{U}}_{\text {stat }}$

$$
\underline{I}_{\text {rot }}^{\prime}=\frac{\underline{U}_{\text {stat }}-\left(R_{\text {stat }}+j \cdot X_{\text {stat }}\right) \cdot \underline{I}_{s t a t}}{j \cdot X_{m}}
$$

Further the rotor voltage can be calculated as a function of speed, stator voltage and stator current

$$
\left.\underline{U}_{r o t}=\frac{\left(\dot{R}_{o t}+j \cdot s \cdot X_{\text {rot }}\right.}{j \cdot X_{m}}\right)-U_{s t a t}\left(\frac{\left(R_{\text {stat }}+j \cdot X_{\text {tat }}\right) \cdot\left(\dot{R}_{o t}+j \cdot s \cdot \dot{X}_{\text {ot }}\right)+s \cdot X_{m}^{2}}{j \cdot X_{m}}\right) I_{s t}
$$

The apparent power processed by the rotor frequency converter is:

$$
\left|\underline{S}_{r o t}\right|=\operatorname{abs}\left(\underline{U}_{r o t}^{\prime} \cdot \underline{I}_{r o t}^{\prime *}\right)
$$

\section{Model description}

Using the program Matlab/Simulink, simulation is made for two wind generation systems whereas one of them is using SCIG and the other uses DFIG at similar simulation conditions. The wind generation systems are connected to the grid. The models that are examined are $9 \mathrm{MW}$ wind farms consisting of six 1.5 MW wind turbines connected to a $25 \mathrm{kV}$ distribution system exporting power to $110 \mathrm{kV}$ grid through a $25 \mathrm{~km} 25 \mathrm{kV}$ feeder (Fig.3). The behavior of the system is estimated by several changes in the wind speed, namely for the nominal wind speed of $9 \mathrm{~m} / \mathrm{s}$ as well as for immediate changes form 6 to $9 \mathrm{~m} / \mathrm{s}$ and from 9 to $12 \mathrm{~m} / \mathrm{s}$. Initially the wind speed is set to $9 \mathrm{~m} / \mathrm{s}$ or $6 \mathrm{~m} / \mathrm{s}$ respectively and then starting at $\mathrm{t}=2 \mathrm{~s}$ wind speeds is rammed to $12 \mathrm{~m} / \mathrm{s}$ or $9 \mathrm{~m} / \mathrm{s}$ in 3 seconds respectively. The same gust of wind is applied to the second and the third turbine, respectively with 2 seconds and 4 seconds delays. The models are phasor models that allow transient stability type studies with long simulation time and in this case the simulation time is 20 seconds. 


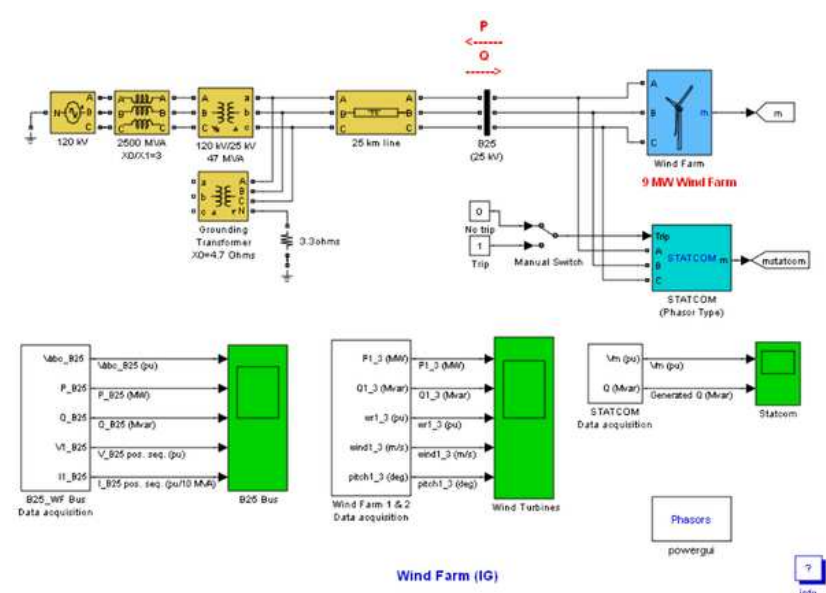

Fig.3. Simulation model

\section{$\underline{\text { 5. Simulation results }}$}

After the simulation the active and reactive power, the generator speed, the wind speed and the pitch angle for each turbine can be monitored from the scope in the model given. Also form the other scope blocks, the voltage, the current, the active and the reactive power of the $25 \mathrm{kV}$ bus can be monitored as well as the reactive power from the statcom.

The results for the wind generation system with SCIG can be seen from the charts given in Fig.4 (where the green colour is for the first turbine, the pink is for the second and the blue is for the third turbine).

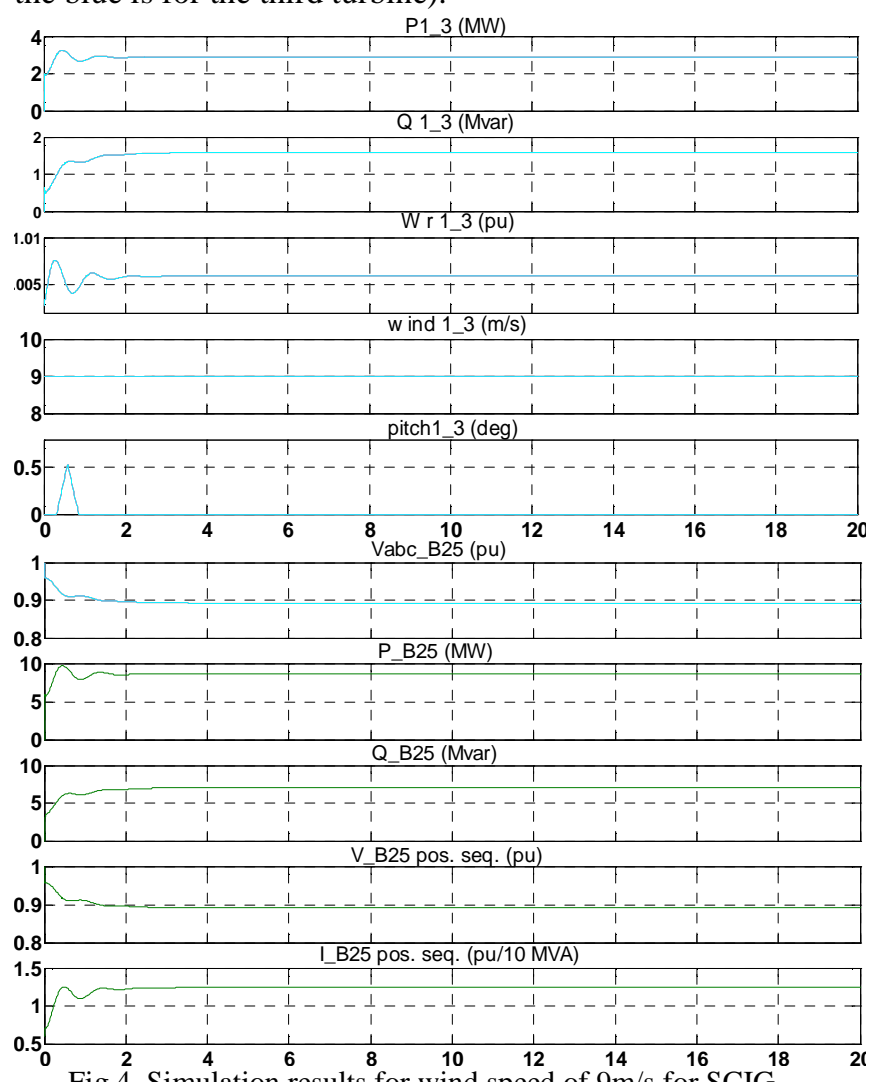

Fig. ${ }^{2}$. Simulation results for wind speed of ${ }^{4} \mathrm{~m}^{14} \mathrm{~s}_{\mathrm{s}}$ for $\mathrm{SCIG}^{16}$
The graphs show which is the non

that when the wind speed is $9 \mathrm{~m} / \mathrm{s}$, nominal speed of the wind in the case of SCIG, the rotor speed Wr of the generator quickly reaches the value of about $1 \mathrm{pu}$ with small variations in the beginning and then remains constant, that monitors wind speed which is also constant. The active power for a short time with slight variations reaches its nominal value of $\quad 3 \mathrm{MW}$ and it is constant for all three turbines. Because in the beginning the value of the active power exceeds $3 \mathrm{MW}$, the pitch angle is activated and returns the value of the active power to the nominal of $3 \mathrm{MW}$. The reactive power also in a short time reaches the value of about 1,5 MVAr and remains constant.

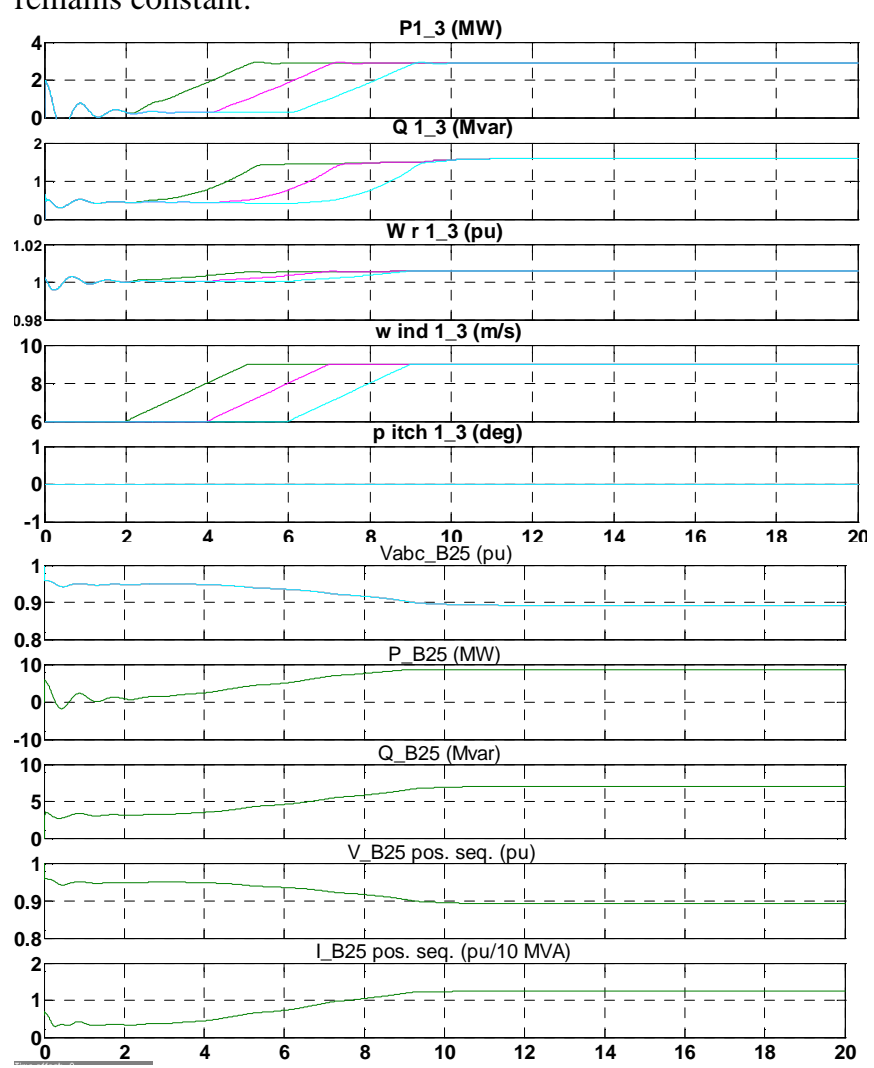

Fig.5. Simulation results for a change in the wind speed from 6 to $9 \mathrm{~m} / \mathrm{s}$ for SCIG

The graphs show that with the change in wind speed of 6-9 $\mathrm{m} / \mathrm{s}$ in the case of SCIG, the rotor speed $\mathrm{Wr}$ of the generator follows the change of wind speed and reaches the value of about $1 \mathrm{pu}$ with small variations in beginning and then remains constant. The active power follows the change of wind speed with small variations in the beginning but once the wind speed reaches the value of 9 $\mathrm{m} / \mathrm{s}$, the active power reaches its nominal value of $3 \mathrm{MW}$ and it is constant for all three turbines, so the pitch angle remains zero. Reactive power also follows the change of wind speed but once the wind speed reaches the value of $9 \mathrm{~m} / \mathrm{s}$, the reactive power reaches the value of 1,5 MVAr and is constant for all three turbines. 

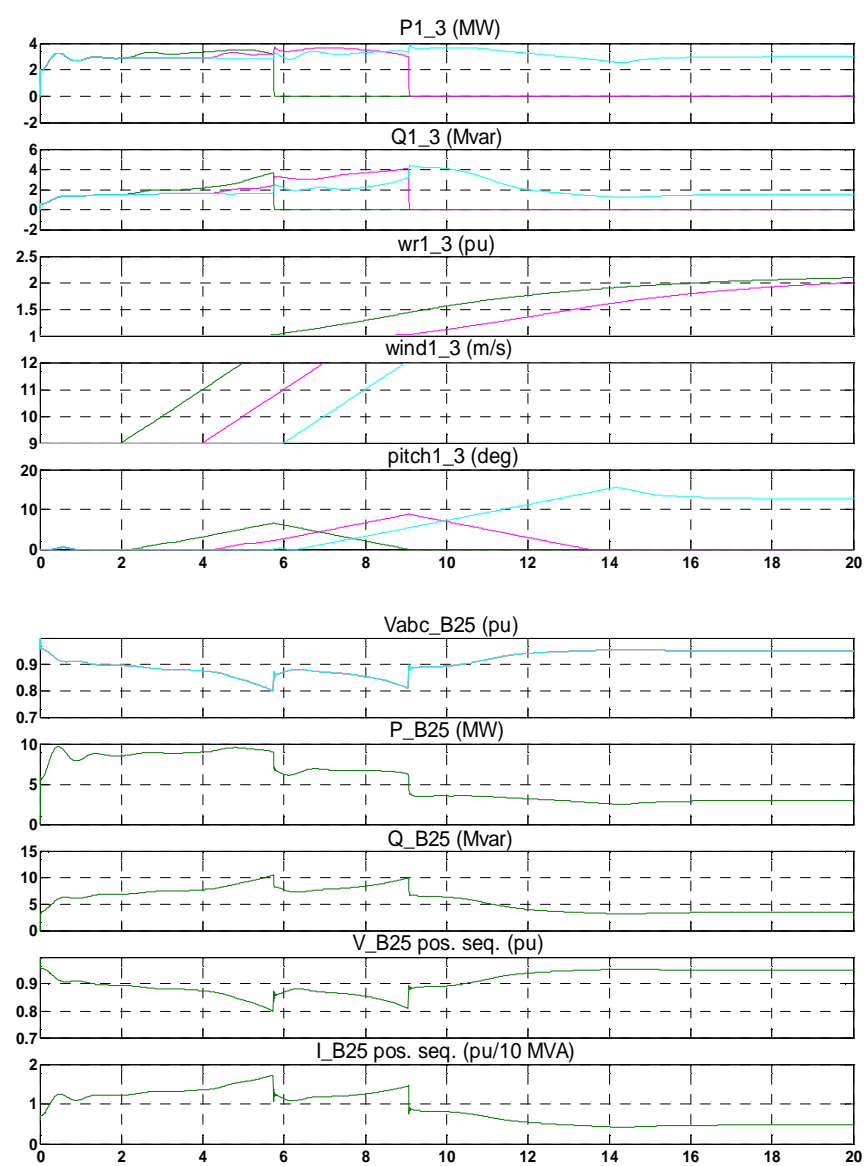

Fig.6. Simulation results for a change in the wind speed from 9 to $12 \mathrm{~m} / \mathrm{s}$ for SCIG

The graphs show that with the change in wind speed of 9$12 \mathrm{~m} / \mathrm{s}$ in the case of SCIG, the rotor speed $\mathrm{Wr}$ of the generator is a constant value of 1 pu except for the first and the second turbine where the rotor speed begins to raise after 6 s or 9 s respectively. The active power for a short time reaches its nominal value of $3 \mathrm{MW}$, and the pitch angles are activated when the value of the active power exceeds $3 \mathrm{MW}$ and returns that value to the nominal. Reactive power also follows the change of the wind speed, i.e. after the exclusion of the two turbines it stabilizes to the value of 1,9 MVAr. The first and the second turbine are excluded form the protection system, more accurate form the AC Undervoltage protection type.

The results for the wind generation system with DFIG can be seen from the following (where the green colour is for the first turbine, the pink is for the second and the blue is for the third turbine).
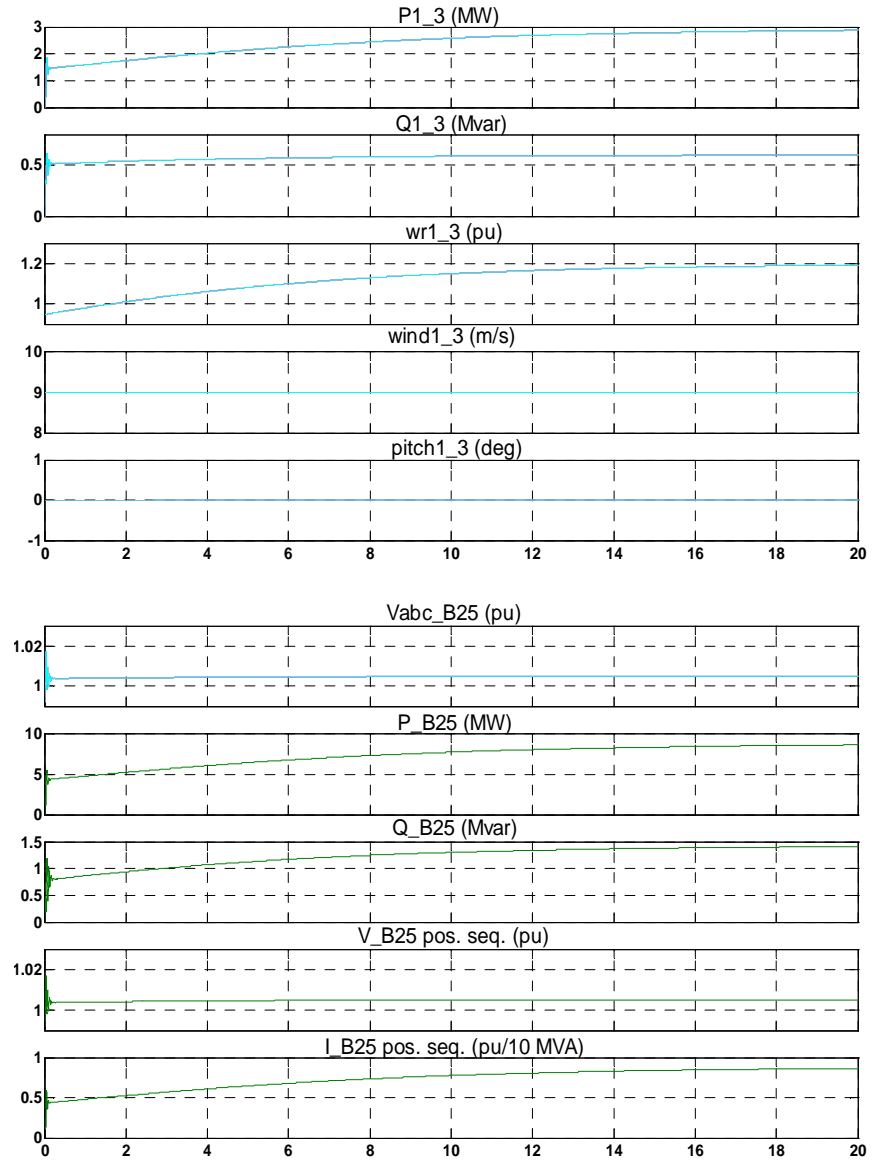

Fig.7. Simulation results for wind speed of $9 \mathrm{~m} / \mathrm{s}$ for DFIG

The graphs show that when the wind speed is $9 \mathrm{~m} / \mathrm{s}$ which is the nominal speed of the wind in the case of DFIG, the rotor speed $\mathrm{Wr}$ of the generator does not follow the change of the wind speed, in fact it grows over time from 0.95 to $1.2 \mathrm{pu}$. The active power follows that change of the rotor speed and later it reaches its value of $3 \mathrm{MW}$. Reactive power is almost constant, while the pitch angle remains zero since the active power does not pass the nominal value of $3 \mathrm{MW}$.

The graphs on Fig 8 show that with the change in wind speed of $6-9 \mathrm{~m} / \mathrm{s}$ in the case of DFIG, the rotor speed $\mathrm{Wr}$ of the generator does not follow the change of the wind speed, in fact it grows over time from 0.95 to $1.2 \mathrm{pu}$. The active power follows that change of the rotor speed and later it reaches its nominal value of 3 MW. Reactive power is almost constant, while the pitch angle remains zero since the active power does not pass the nominal value of $3 \mathrm{MW}$. 

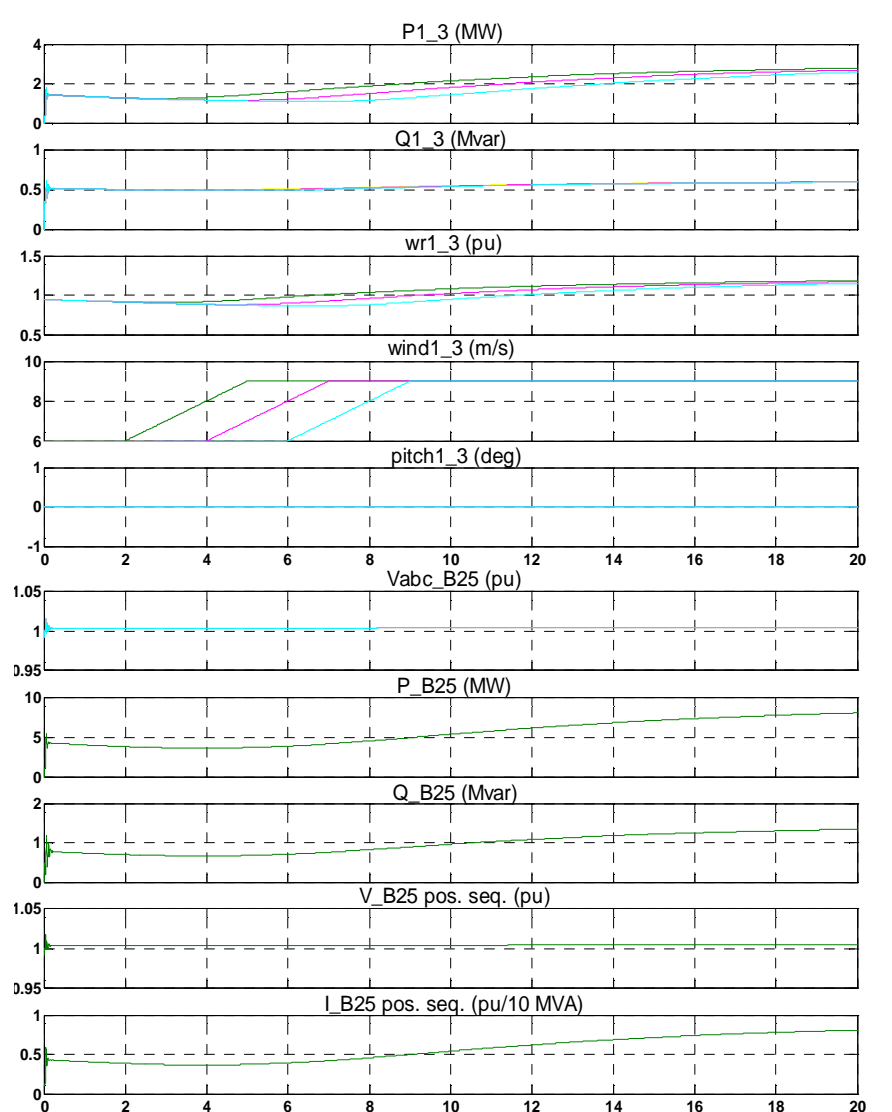

Fig.8. Simulation results for a change in the wind speed from 6 to $9 \mathrm{~m} / \mathrm{s}$ for DFIG

The graphs on Fig.9 show that with the change in wind speed of $9-12 \mathrm{~m} / \mathrm{s}$ in the case of DFIG, the rotor speed $\mathrm{Wr}$ of the generator does not follow the change of the wind speed, in fact it grows over time from $1 \mathrm{pu}$ to $1.9 \mathrm{pu}$. The active power follows the change of the wind speed but later it reaches its value of $3 \mathrm{MW}$. Reactive power is almost constant, while the pitch angle increasing with time.

\section{Conclusion}

From these simulation results the following conclusion can be estimated: in the wind generation system with SCIG the active power reaches its nominal value faster than in the wind generation systems with DFIG where the active power reaches its nominal value later. The rotor speed of the generator in the DFIG system continues to grow in time although the wind speed is constant.

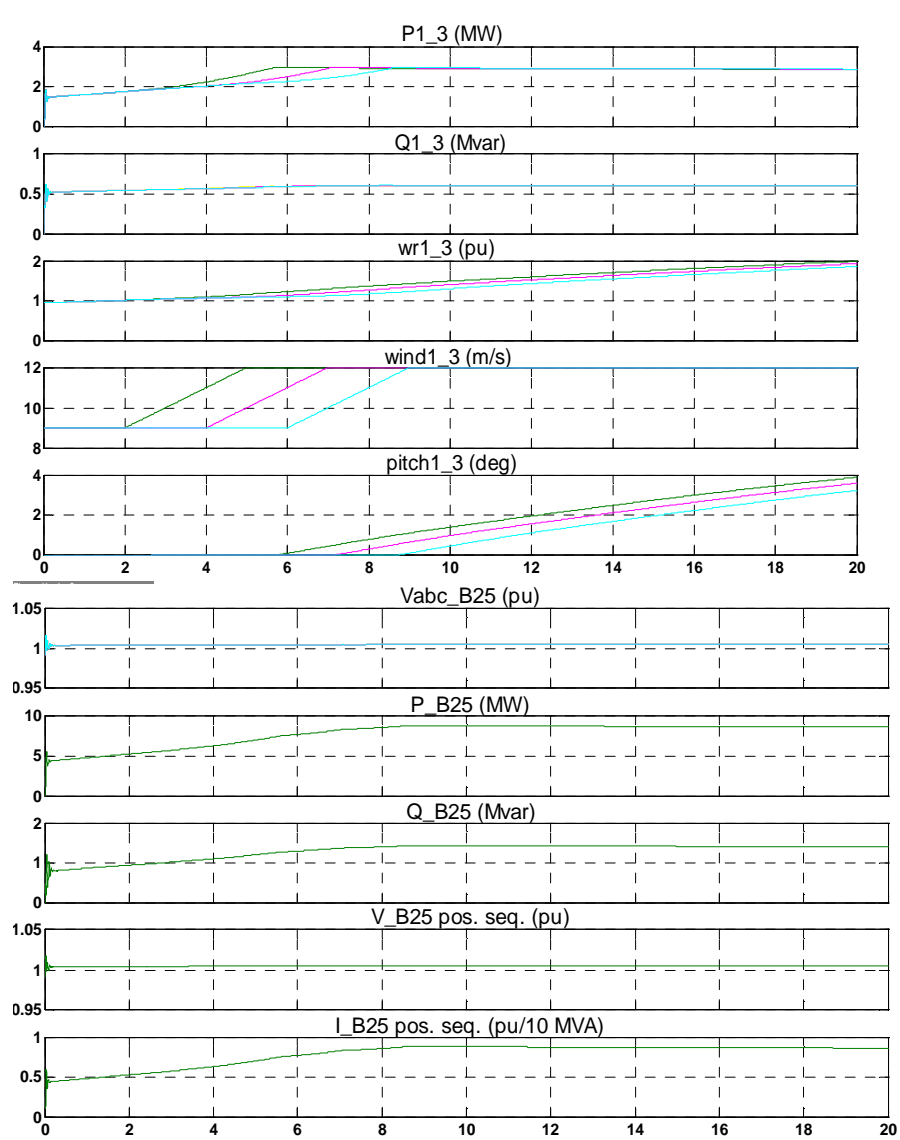

Fig.9. Simulation results for a change in the wind speed from 9 to $12 \mathrm{~m} / \mathrm{s}$ for DFIG

\section{$\underline{\text { References }}$}

[1] Wind energy fundamentals, resource analysis \&economics Sathyajith Mathew (Springer 2006)

[2] Integrating Wind - Developing Europe's power market for the large-scale integration of wind power - EWEA February (2009)

[3] Analysis, Modeling and Control of DFIG for WT - Andeas

Petersson (Chalmers Bibliotek Sweeden 2005)

[4] Wind Energy - Renewable Energy and the Environment -

Vaughn Nelson (Taylor\&Francis Group 2009)

[5] Dynamic simulations of electric machinery using

Matlab/Simulink - Chee-Mun Ong (Prenticie Hall 1998)

[6]Doubly Fed Induction Machine:Operating regions and

Dynamic Simulation - Joris Soens, Karel de Brabandere, Johan

Driesen, Ronnie Belmans (EPE 2003- Touluse)

[7] Variable speed wind power generation using DFIG-a comparison with alternative schemes - Rajib Datta and

V.T.Ranganathan (IEEE Transactions on Energy Conversion2002)

[8] Wind energy system - Gary L.Johnson (Manhattan KS 2006 